\title{
Age variation of cephalic index according to cross-sectional studies of schoolchildren
}

\section{DOI: http://doi.org/10.26758/9.1.14}

\author{
Tatyana HURBO (1), Inessa SALIVON (1)
}

Institute of History of the National Academy of Sciences of Belarus

Address correspondence to: Tatyana Hurbo, Department of Anthropology, Institute of History of the National Academy of Sciences of Belarus, komn. 213, ul. Akademicheskaya, 1, 220072, Minsk, Belarus. Ph.: +375-17-284-27-96; Fax: +375-17-284-18-70; E-mail: hurbo@ mail.ru

\begin{abstract}
Objective. The objective of the study is to reveal the age-related variability of the cephalic index in schoolchildren according to the cross-sectional and longitudinal studies.

Material and methods. The basis for the study was data on the head shape of schoolchildren from town of Miory, Vitebsk Region, aged 6-17 (transverse study in 2002-2003, 1194 children) and schoolchildren from Minsk, aged 7-17 (longitudinal study of the 1980 ${ }^{\text {th }}, 254$ children, 1223 measurements). Two craniofacial measurements were taken: head length (g-op), head breadth (eu-eu), the cephalic index was calculated.
\end{abstract}

Results. The leading morphotype for the two studied groups is brachycephalic. In Miory, the frequency of occurrence of the mesocephalic head shape is higher $(\mathrm{p}<0.05)$ and the frequency of the hyperbrachycephalic and ultrabrachycephalic shape is lower compared to Minsk. From 7 to 17 years, in Miory both in boys and the girls, the average values of the cephalic index increased by 1.6 units, in Minsk - decreased by 0 4-0.8. The age variability of head sizes is due to the different growth rates of the head length and breadth and regional features of this process. According to a longitudinal study, in $23 \%$ the head shape type between the ages of 6-7 differed from the shape between the ages of 16-17 years, usually (19.2\%) it was a transition from higher values to lower values (from brachymorphic to mesomorphic shape, etc.).

Conclusions. Changes in the head shape during the growth period should be taken into account when analyzing the variability of the cephalic index.

Keywords: head length and breadth, cephalic index, transverse and longitudinal studies, age variability.

\section{Introduction}

Since the very beginning of the development of anthropological science, the study of changes with time of the overall size and shape of the head (circumference, head length and breadth, cephalic index) in humans was of special interest of scientists: "It all started in 1844, when a famous Swedish anthropologist Anders Retzius began to measure skulls. He did this in an extremely primitive way - he measured the width and the length of the braincase and then calculated the width to length ratio, which he named cephalic index" (Alekseev, 1972; Franco et al., 2013). Later, these dimensions began to be used when comparing living people and their ratio became known as the cephalic index. People were subdivided into dolichocephalic (long headed) and brachycephalic (round headed). This marked the start for the measurement of individual elements of the head and face structure, and the introduction of the first measurement properties into anthropology that were considered the most important among all others for a long time. 
One of the most striking tendencies in the shape change of the cerebral part of skull in the Slavic population of the East European Plain during the last millennium, noted by the Russian anthropologists Bogdanov, Debets, Alekseeva and others, was a tendency of brachycephalization, i.e., "rounding" of the skull shape due to the shortening of the longitudinal and expansion of the transverse diameters (Khit, 1968; Purunjan et al., 2002). The issues of epochal variability of the skull size and shape in people living in Belarus were identified by Salivon, who, based on the craniological and cephalometric data received by her, showed a directional process of brachycephalization that was occurring throughout the $2^{\text {nd }}$ millennium $\mathrm{AD}$, which made it possible to express a hypothesis about its microevolutionary nature (Salivon, 2011). However, the $20^{\text {th }}$ century made some adjustments to this process. More and more authors in different countries began to talk about the opposite tendency of structural transformation towards dolichocephalization (or debrachycephalization) of the head in modern humans (Kouchi, 2000; Pavlica et al., 2018; Salivon, 2008; Tineshev and Dimov, 2013).

In addition to studying the epochal variability of the cephalic index, it is also important to study its age variability. The patterns in the development of head and face size in children in the process of growth were discussed by anthropologists as exemplified in the cross-sectional studies in the middle of the $20^{\text {th }}$ century (Miklashevskaya, 1968; Miklashevskaya, Solovyova and Godina, 1988). The main type of the growth curve expressing the growth patterns of the majority of head and face sizes in children in postnatal development is a parabola of the $3^{\text {rd }}$ order. The most intensive growth of the head occurs in the first years of life, then the growth gradually decreases, reaching a minimum. During puberty, the growth begins again, which ends with the end of puberty. Great similarity was found in the age dynamics among the members of different ethnic and racial groups. However, there is not enough information on the age dynamics of the head size and the braincase shape obtained as a result of the longitudinal studies. Often, children of different ages are combined into one group, without taking into account possible changes in the shape of child head during growth (Akinbami, 2014; Vojdani et al., 2009). The objective of our study is to reveal the age-related variability of the cephalic index in schoolchildren according to the transverse and longitudinal studies.

\section{Material and methods}

In 2002-2003, Hurbo conducted an anthropometric measurement of the head and face sizes in children aged 6-17 in the town of Miory, Vitebsk region, Belarus. Miory is a small district center with a population of 9.3 thousand people; the industry is represented by food, mixed feed and flax processing facilities. Miory district is a border area, having a common border with Latvia in the north. In total, the city has 3 schools, where 1194 children were examined (593 boys and 601 girls) according to the standard anthropometric program.

From 1982 to 1991, Salivon performed a longitudinal anthropometric study of 149 boys and 105 girls of Minsk, the capital of the Republic of Belarus. In total, 1223 measurements have been carried out within 11 years. Minsk is the largest city in Belarus, is a political, economic, cultural and scientific center of the republic. According to the 1989 census, the population of Minsk was more than 1 million 600 thousand people.

Due to the fact that only 6-89 children represented a group of the same age, and at classifying them by morphotypes, the subgroups obtained were very small, we distinguished four age intervals to trace the age variability of the morphotypes: 6-9, 10-12, 13-15 and 16-17 years of age.

When considering the properties of the head shape based on the cephalic index value, different variants of the head shape are distinguished. There are various classifications of the head shape. For example, one of them distinguishes 3 shape types. With a cephalic index of not more than 74.9, it is dolichocephaly (long head), with a cephalic index ranging from 75.0 to 79.9 
- it is mesocephaly (moderate head), and with a cephalic index greater than 80.0 - it is brachycephaly (short head, or round head). However, more extensive classifications are used quite often, for example, Broca's one, with 5 morphotypes, and others (Rauten et al., 2014).

We have used the following scheme for classifying the morphotypes: variations of the cephalic index from 70.0 to 74.9 inclusively belong to the dolichocephalic morphotype, from 75.0 to 79.9 - to the mesocephalic, from 80.0 to 84.9 - to the brachycephalic; to the hyperbrachycephalic - from 85.0 to 89.9 , and to the ultrabrachycephalic - from 90.0 and more (Williams et al., 1995).

In order to trace how the cephalic index of one person changes with age, we selected from the whole group of children of Minsk those whose head sizes were measured during the entire observation period, i.e. between the ages of 7 to 17 (these are 10-11 years of observations). We obtained a group of 28 boys and 24 girls. Since the differences by the cephalic index were statistically insignificant, we united them into one group of 52 children.

All studies were carried out in accordance with the procedures of bioethics. The same measurement protocol was used in our investigations. The head and face sizes were measured according to the standard anthropometric method (Bunak, 1941; Williams et al., 1995). The large spreading calipers were used for the measurements. Two craniofacial measurements were taken: head length (g-op), head breadth (eu-eu). The cephalic index was calculated from head breadth (eu-eu) and head length (g-op) as:

$\mathrm{CI}=$ Head breadth (eu-eu) $\times 100 /$ Head length $(\mathrm{g}-\mathrm{op})$.

Statistical analyses of the obtained data were conducted by mean Statistica 7 software. Basic descriptive statistics were computed: Means and standard deviation values (SD). The Student's t-test and Pearson's chi-square test were used for evaluating age differences between groups. $\mathrm{P}$ value $<0.05$ was considered statistically significant. As the numbers per age group are small, confidence intervals $(95 \% \mathrm{CI})$ for all percent values were determined.

\section{Results}

Tables 1 and 2 present the age variability of the head length and breadth, as well as the cephalic index in Minsk and Miory.

The head's length of Miory boys aged between 6 and 17 years old increased by $9.9 \mathrm{~mm}$ (almost $1 \mathrm{~cm}$ ), respectively by $5.9 \mathrm{~mm}$ in girls. Since we conducted the transverse study, and the individual variability of the head sizes, including the diameters, could be more significant than the age variability, we also indicated negative dynamics of values in certain periods. For example, the average intergroup values of the head length in girls decreased at the age of 6-8, 9$10,11-12$ (at 7-8 and 11-12 at $\mathrm{p}<0.05$ ), in boys - at the age of 9-10,12-13. A certain increase in the average group values was recorded in girls at the age of 8-9 and 10-11 (by 3.9 and $2.8 \mathrm{~mm}$, respectively, p < 0.001), in boys - at the age of 7-8 (by $3.4 \mathrm{~mm}, \mathrm{p}<0.001$ ), and 10-11, 13-15 (by 1.9-2.2 mm annually, $\mathrm{p}<0.05$ ).

The head's length of Minsk boys aged between 7 and 17 years old increased by 14.1, respectively by $10.2 \mathrm{~mm}$ in girls. The most active period of increase in the head length in boys was recorded at the age of 12-16, when its average value was increasing by 1.8-2.3 mm each year. In girls, the maximum increments of the average values of this diameter were observed at $11-12(+2.8 \mathrm{~mm}, \mathrm{p}<0,05)$ and $13-14(+2.0 \mathrm{~mm})$; at the age of 12-13, there was a negative trend, which was probably influenced by the small number of children examined at the age of 12 (only 26 children).

The head's breadth of Miory boys increased between the ages of 6 and 17 years old by $8.5 \mathrm{~mm}$, respectively by $7.7 \mathrm{~mm}$ in girls. The maximum increments of the average group values of the index in girls were observed at the age of 10-11 and 12-13 (by 3.0-3.3 mm, p < 0.001); significant gains were also observed at the age of 8-9 (by $1.9 \mathrm{~mm}, \mathrm{p}<0.01$ ) and 16-17 (by 1.5 
$\mathrm{mm}, \mathrm{p}<0.05)$. For boys, the head's breadth most actively incremented at the age of $7-8$ years old (by $2.7 \mathrm{~mm}, \mathrm{p}<0.001$ ), 10-11 and 12-13 years old (by 1.5 and $1.6 \mathrm{~mm}$, respectively, $\mathrm{p}<$ 0.05 ), as well as 13-14 years old (by $2.2 \mathrm{~mm}$, p < 0.01 ).

The head's breadth of Minsk boys increased by $10.1 \mathrm{~mm}$, respectively by $7.6 \mathrm{~mm}$ in girls. In both the boys and the girls, the maximum increments of the average values of this diameter occurred at the age of 7-8 (by 1.8 and $1.3 \mathrm{~mm}$, respectively) and at the age of 12-13 (by 1.7 and $2.7 \mathrm{~mm}$, in girls $-\mathrm{p}<0.05$ ). A slight negative trend was recorded at the age of 10-11 in boys and at the age of 13-14 and 15-16 in girls. Apparently, such trend took place due to the fact that the composition of the examined children varied, and it was not always possible to measure each child annually.

The cephalic index in boys of Miory was in the range of 80.0-82.2, in girls - in the range of 80.1-82.1, still showing a slight increase in values: for example, while at the age of 6-11 years the cephalic index was 80-81 both in boys and the girls, while it was mainly 81-82 at the age of 12-17 years old. In boys, an increase in the cephalic index at the age of 9-10 and 12-13 years old (by 1.1 and 1.5 units) reached a level of statistical significance $(\mathrm{p}<0.05$, respectively $\mathrm{p}$ $<0.01)$.

In boys of Minsk, the cephalic index varied in the range of 81.4-83.1: while it was predominantly increasing in the age range of 7-10, reaching its maximum at the age of 10 , it was steadily declining between the ages of 12 to 17 , reaching the minimum value of 81.4. Perhaps the reason for such dynamics of the index is the alternation of the acceleration of the growth of either longitudinal, or transverse head sizes, that is, in a wavelike growth process. In general, the average value of the cephalic index decreased by 0.8 between 7 and 17 years of age. In girls, the cephalic index was in the range of 81.7-83.4, increasing and decreasing, and reducing in general by 0.4 between the ages of 7 to 17 . The maximum increase in the value of the cephalic index took place at $12-13$ years old $(+1.7, \mathrm{p}<0.05)$, after which there was a tendency to decrease in its values.

Regarding the head shape of Miory boys, the dolichocephalic head shape was extremely rare (2.8-5.8\% in certain age periods, $4.6 \%$ in the total sample). The mesocephalic head shape was typical for $22.4-45.5 \%$ (34.4\% in the total sample) of the boys. Its occurrence is maximum at the age of 6-9 and minimum at the age of 16-17 years old. The brachycephalic morphotype was more common than the others: its frequency varied in the range of 40.4-48.6\% (45.4\% in the total sample). The hyperbrachycephalic shape of the head was typical for $7.7-24.3 \%$ (14.8\% on average) of the boys of Miory, progressively increasing from 6-9 to 16-17 years old. The ultrabrachycephalic morphotype was encountered in isolated cases (0.6-1.3\%).

The girls of Miory, like the boys, had extremely rare cases of dolichocephalic and ultrabrachycephalic shapes of the head: $0.9-6.4 \%$ in certain age samples of the examined children (3.8\% in the total sample), and 0.6-2.9\% (1.0\%), respectively. Mesocephalic shape was encountered in $27.9-39.2 \%$ of cases (33.0\% in the total sample). The most typical head shape in girls of Miory is brachycephalic (43.7-51.4\% at certain ages, $46.9 \%$ in the total sample), and the hyperbrachycephalic shape is somewhat rarer $(10.2-20.6 \%$ at certain ages, $15.3 \%$ in the total sample).

As with certain ages, the following trend can be observed when grouping the data into intervals. With aging (between 6 and 17 years of age), the proportion of dolichocephalic and mesocephalic shapes decreases, while the proportion of brachycephalic and hyperbrachycephalic shapes increases.

In children of Minsk, the least common is ultrabrachycephalic and dolichocephalic head shape. In boys of different age groups, the ultrabrachycephalic morphotype was noted in 2.7$4.5 \%$ of cases ( $4.0 \%$ in the total sample), in girls - in $0.0-2.3 \%$ (1.7\% in total), dolichocephalic morphotype - in 2.8-6.8 (4.4\%) and $1.7-3.2 \%$ of cases $(2.3 \%)$, respectively. Most often, the children living in the capital had a brachycephalic head shape: in boys, at different age periods, 
its frequency varies in the range of $42.4-51.9 \%$ (46.6\% in the total sample), in girls - in the range of $47.1-57.0 \%$ (53.0\% on average). The mesocephalic morphotype was typical for $19.1-29.1 \%$ of boys $(24.7 \%$ in the total sample) and $17.3-24.7 \%$ of girls $(21.2 \%$ in total), hyperbrachycephalic - for $18.2-23.7 \%$ (20.3\%) and $15.1-25.7 \%$ (21.8\%) of children, respectively.

With aging, there was a decrease in the proportion of children with hyperbrachycephalic shape, and an increase of brachycephalic head shape in girls and dolichocephalic head shape in boys.

The analysis of the variability of the cephalic index in children of Minsk between the ages of 7 to 17, who were observed over all 10-11 years, showed that the value of the cephalic index decreased with age in children in $75 \%$ of cases, increased in $21.2 \%$, and remained unchanged in $3.8 \%$. The range of variability is significant - from -4.3 to +5.9 , i.e. the cephalic index could both decrease by 4.3 , and increase by 5.9 , and on average the cephalic index decreased by 0.8 . In $21.2 \%$, the cephalic index changed by more than \pm 2.0 (fig. 1 ).

In most cases $(53.9 \%)$, the value of the cephalic index varied within the same morphotype; in $23.1 \%$ of cases, the morphotype returned to the original category by the end of the observation period, even if it changed during the school period. Only in $23 \%$, the head shape type between the ages of 6-7 differed from the shape between the ages of 16-17 years, usually (19.2\%) it was a transition from higher values to lower values (from brachymorphic to mesomorphic shape, etc.).

Figure 1. Shifts of cephalic index values from 7 to 17 years at children of Minsk

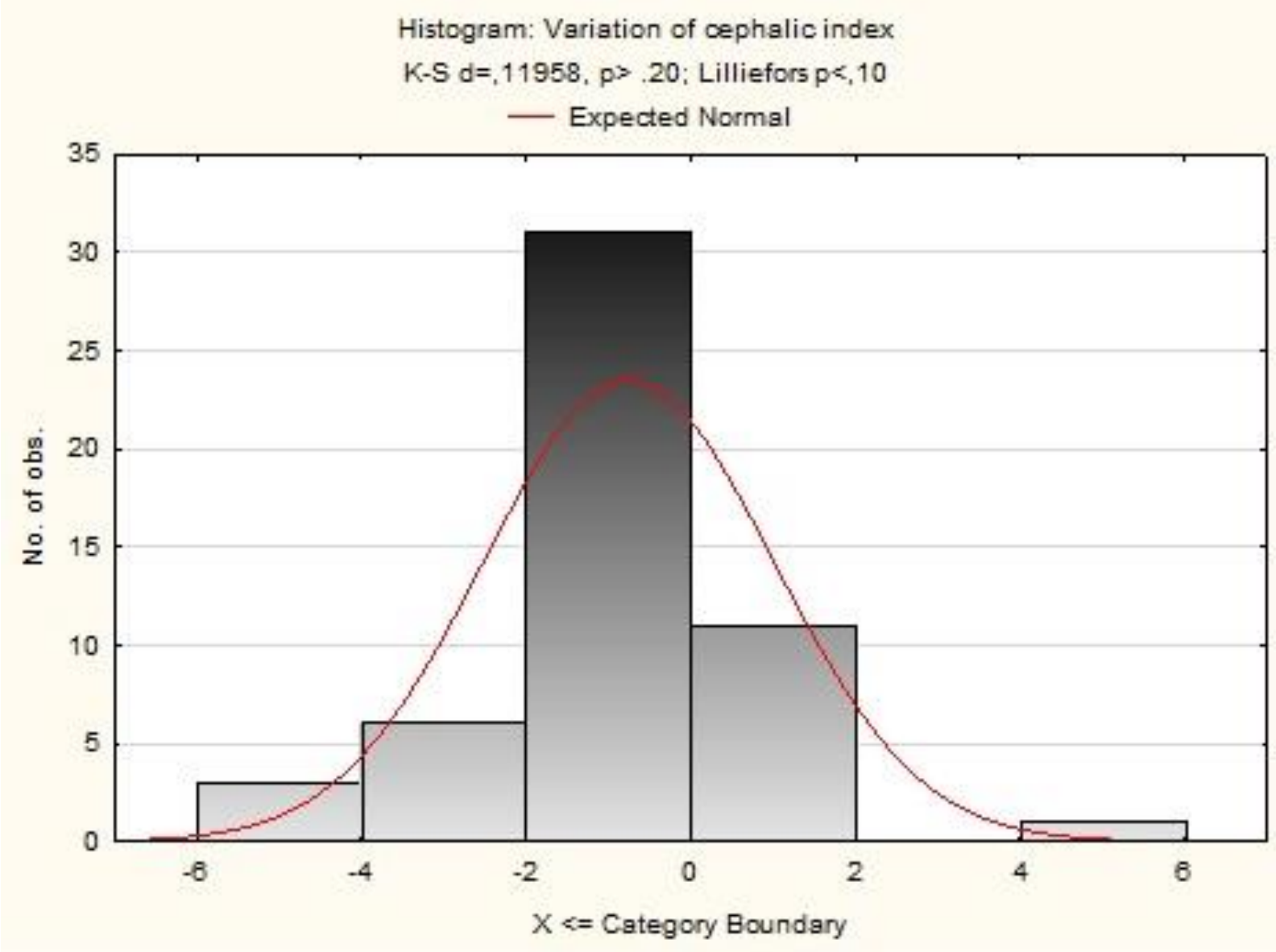


Table 1. Head dimensions and cephalic indices of studied boys

\begin{tabular}{|c|c|c|c|c|c|c|c|c|c|c|c|c|c|c|}
\hline \multirow{3}{*}{$\begin{array}{l}\text { Age, } \\
\text { years }\end{array}$} & \multicolumn{7}{|c|}{ Minsk } & \multicolumn{7}{|c|}{ Miory } \\
\hline & \multirow[t]{2}{*}{$\mathrm{N}$} & \multicolumn{2}{|c|}{ head length, $\mathrm{mm}$} & \multicolumn{2}{|c|}{ head breadth, $\mathrm{mm}$} & \multicolumn{2}{|c|}{ cephalic index } & \multirow[t]{2}{*}{$\mathrm{N}$} & \multicolumn{2}{|c|}{ head length, $\mathrm{mm}$} & \multicolumn{2}{|c|}{ head breadth, mm } & \multicolumn{2}{|c|}{ cephalic index } \\
\hline & & Mean & SD & Mean & SD & Mean & SD & & Mean & SD & Mean & SD & Mean & $\mathrm{SD}$ \\
\hline 7 & 40 & 178.5 & 5.8 & 146.5 & 5.8 & 82.2 & 3.9 & 46 & 178.5 & 5.9 & 143.2 & 5.4 & 80.3 & 3.6 \\
\hline 8 & 70 & 179.5 & 6.9 & 148.3 & 5.1 & 82.7 & 4.0 & 46 & 181.9 & 7.0 & 145.9 & 4.7 & 80.3 & 3.4 \\
\hline 9 & 67 & 180.5 & 7.0 & 149.4 & 5.8 & 82.9 & 4.4 & 55 & 182.1 & 5.6 & 145.6 & 4.6 & 80.0 & 3.6 \\
\hline 11 & 57 & 182.4 & 6.2 & 150.3 & 5.8 & 82.5 & 4.1 & 49 & 182.7 & 6.5 & 147.8 & 4.6 & 81.0 & 3.4 \\
\hline 12 & 38 & 183.3 & 6.6 & 151.6 & 6.2 & 82.8 & 4.0 & 51 & 183.6 & 7.3 & 147.4 & 4.6 & 80.4 & 3.8 \\
\hline 13 & 73 & 185.6 & 6.7 & 153.3 & 6.0 & 82.7 & 4.4 & 68 & 182.1 & 8.5 & 149.0 & 6.8 & 81.9 & 3.1 \\
\hline 14 & 83 & 187.5 & 7.4 & 154.4 & 6.1 & 82.5 & 4.3 & 64 & 184.3 & 7.8 & 151.2 & 3.7 & 82.2 & 3.9 \\
\hline 15 & 88 & 189.6 & 7.0 & 155.4 & 6.4 & 82.0 & 4.2 & 46 & 186.5 & 8.0 & 151.3 & 5.1 & 81.2 & 4.4 \\
\hline
\end{tabular}


Table 2. Head dimensions and cephalic indices of studied girls

\begin{tabular}{|c|c|c|c|c|c|c|c|c|c|c|c|c|c|c|}
\hline \multirow{3}{*}{$\begin{array}{l}\text { Age, } \\
\text { years }\end{array}$} & \multicolumn{7}{|c|}{ Minsk } & \multicolumn{7}{|c|}{ Miory } \\
\hline & \multirow[t]{2}{*}{$\mathrm{N}$} & \multicolumn{2}{|c|}{ head length, mm } & \multicolumn{2}{|c|}{ head breadth, mm } & \multicolumn{2}{|c|}{ cephalic index } & \multirow[t]{2}{*}{$\mathrm{N}$} & \multicolumn{2}{|c|}{ head length, mm } & \multicolumn{2}{|c|}{ head breadth, mm } & \multicolumn{2}{|c|}{ cephalic index } \\
\hline & & Mean & $\mathrm{SD}$ & Mean & SD & Mean & SD & & Mean & SD & Mean & SD & Mean & SD \\
\hline 7 & 24 & 174.0 & 6.0 & 142.8 & 4.5 & 82.2 & 4.2 & 46 & 176.1 & 6.3 & 141.5 & 4.1 & 80.4 & 3.7 \\
\hline 8 & 57 & 175.1 & 5.9 & 144.1 & 4.8 & 82.4 & 3.7 & 47 & 173.8 & 7.6 & 140.3 & 4.9 & 80.8 & 3.1 \\
\hline 11 & 48 & 177.4 & 5.6 & 146.4 & 5.2 & 82.6 & 3.8 & 53 & 180.4 & 5.5 & 145.2 & 5.1 & 80.5 & 3.0 \\
\hline 12 & 26 & 180.2 & 5.6 & 147.0 & 4.8 & 81.7 & 3.5 & 54 & 178.6 & 5.8 & 144.8 & 5.2 & 81.2 & 3.5 \\
\hline 13 & 52 & 179.5 & 5.7 & 149.7 & 5.0 & 83.4 & 3.0 & 66 & 180.6 & 6.0 & 148.1 & 5.0 & 82.1 & 3.5 \\
\hline 14 & 59 & 181.5 & 5.9 & 149.4 & 5.5 & 82.4 & 3.3 & 48 & 180.6 & 7.0 & 148.2 & 5.5 & 82.1 & 3.8 \\
\hline 15 & 62 & 182.5 & 5.4 & 150.5 & 4.8 & 82.6 & 3.4 & 61 & 181.2 & 7.0 & 147.6 & 5.1 & 81.6 & 4.3 \\
\hline
\end{tabular}


Table 3. Frequencies of the categories of head types according to boys cephalic index values

\begin{tabular}{|c|c|c|c|c|c|c|c|c|c|c|c|c|c|c|c|c|}
\hline \multirow{2}{*}{$\begin{array}{c}\text { Age } \\
\text { groups }\end{array}$} & \multirow[t]{2}{*}{$\mathrm{N}$} & \multicolumn{3}{|c|}{ Dolichocephalic } & \multicolumn{3}{|c|}{ Mesocephalic } & \multicolumn{3}{|c|}{ Brachycephalic } & \multicolumn{3}{|c|}{ Hyperbrachycephalic } & \multicolumn{3}{|c|}{ Ultrabrachycephalic } \\
\hline & & $\mathrm{n}$ & $\%$ & $95 \% \mathrm{CI}$ & $\mathrm{n}$ & $\%$ & $95 \% \mathrm{CI}$ & $\mathrm{n}$ & $\%$ & $95 \% \mathrm{CI}$ & $\mathrm{n}$ & $\%$ & $95 \% \mathrm{CI}$ & $\mathrm{n}$ & $\%$ & $95 \% \mathrm{CI}$ \\
\hline $7-9$ & 177 & 5 & 2.8 & $1.2-6.4$ & 47 & 26.6 & $20.6-33.5$ & 75 & 42.4 & $35.3-49.7$ & 42 & 23.7 & $18.1-30.5$ & 8 & 4.5 & $2.3-8.7$ \\
\hline $13-15$ & 244 & 11 & 4.5 & $2.5-7.9$ & 58 & 23.8 & $18.9-29.5$ & 119 & 48.8 & $42.6-55.0$ & 45 & 18.4 & $4.1-23.8$ & 11 & 4.5 & $2.5-7.9$ \\
\hline $16-17$ & 148 & 10 & 6.8 & $3.7-12.0$ & 43 & 29.1 & $22.3-36.8$ & 64 & 43.2 & $35.5-51.3$ & 27 & 18.2 & $12.9-25.2$ & 4 & 2.7 & $1.1-6.7$ \\
\hline $7-17$ & 700 & 31 & 4.4 & $3.1-6.2$ & 173 & 24.7 & $21.7-28.0$ & 326 & 46.6 & $42.9-50.3$ & 142 & 20.3 & $17.5-23.4$ & 28 & 4.0 & $2.8-5.7$ \\
\hline $10-12$ & 152 & 8 & 5.3 & $2.7-10.0$ & 53 & 34.9 & $27.8-42.7$ & 71 & 46.7 & $39.0-54.6$ & 18 & 11.8 & 7.6-17.9 & 2 & 1.3 & $0.4-4.7$ \\
\hline $13-15$ & 178 & 5 & 2.8 & $1.2-6.4$ & 56 & 31.5 & $25.1-38.6$ & 83 & 46.6 & $39.5-54.0$ & 32 & 18.0 & $13.0-24.3$ & 2 & 1.1 & $0.3-4.0$ \\
\hline 16-17 & 107 & 5 & 4.7 & $2.0-10.5$ & 24 & 22.4 & $15.6-31.2$ & 52 & 48.6 & $39.3-58.0$ & 26 & 24.3 & $17.2-33.2$ & 0 & 0.0 & $0.0-3.5$ \\
\hline $6-17$ & 593 & 27 & 4.6 & $3.2-6.5$ & 204 & 34.4 & $30.7-38.3$ & 269 & 45.4 & 41.4-49.4 & 88 & 14.8 & $12.2-17.9$ & 5 & 0.8 & $0.4-2.0$ \\
\hline
\end{tabular}

Table 4. Frequencies of the categories of head types according to girls cephalic index values

\begin{tabular}{|c|c|c|c|c|c|c|c|c|c|c|c|c|c|c|c|c|}
\hline \multirow{2}{*}{$\begin{array}{c}\text { Age } \\
\text { groups }\end{array}$} & \multirow[t]{2}{*}{$\mathrm{N}$} & \multicolumn{3}{|c|}{ Dolichocephalic } & \multicolumn{3}{|c|}{ Mesocephalic } & \multicolumn{3}{|c|}{ Brachycephalic } & \multicolumn{3}{|c|}{ Hyperbrachycephalic } & \multicolumn{3}{|c|}{ Ultrabrachycephalic } \\
\hline & & $\mathrm{n}$ & $\%$ & $95 \% \mathrm{CI}$ & $\mathrm{n}$ & $\%$ & $95 \% \mathrm{CI}$ & $\mathrm{n}$ & $\%$ & $95 \% \mathrm{CI}$ & $\mathrm{n}$ & $\%$ & $95 \% \mathrm{CI}$ & $\mathrm{n}$ & $\%$ & $95 \% \mathrm{CI}$ \\
\hline \multicolumn{17}{|c|}{ Minsk } \\
\hline $7-9$ & 140 & 4 & 2.9 & $1.1-7.1$ & 31 & 22.1 & $16.1-29.7$ & 66 & 47.1 & $39.1-55.4$ & 36 & 25.7 & $19.2-33.5$ & 3 & 2.2 & $0.7-6.1$ \\
\hline $10-12$ & 117 & 2 & 1.7 & $0.5-6.0$ & 27 & 23.1 & $16.4-31.5$ & 60 & 51.3 & $42.3-60.2$ & 26 & 22.2 & $15.6-30.6$ & 2 & 1.7 & $0.5-6.0$ \\
\hline $13-15$ & 173 & 3 & 1.7 & $0.6-5.0$ & 30 & 17.3 & $12.4-23.7$ & 98 & 56.7 & $49.2-63.8$ & 38 & 22.0 & $16.4-28.7$ & 4 & 2.3 & $0.9-5.8$ \\
\hline $16-17$ & 93 & 3 & 3.2 & $1.1-9.1$ & 23 & 24.7 & $17.1-34.4$ & 53 & 57.0 & $46.9-66.6$ & 14 & 15.1 & $9.2-23.7$ & 0 & 0.0 & $0.0-4.0$ \\
\hline $7-17$ & 523 & 12 & 2.3 & $1.3-4.0$ & 111 & 21.2 & $17.9-24.9$ & 277 & 53.0 & $48.7-57.2$ & 114 & 21.8 & $18.5-25.5$ & 9 & 1.7 & $0.9-3.2$ \\
\hline \multicolumn{17}{|c|}{ Miory } \\
\hline $7-9$ & 158 & 9 & 5.7 & $3.0-10.5$ & 62 & 39.2 & $32.0-47.0$ & 69 & 43.7 & $36.2-51.5$ & 18 & 11.4 & $7.3-17.3$ & 0 & 0.0 & $0.0-2.4$ \\
\hline $10-12$ & 157 & 10 & 6.4 & $3.5-11.3$ & 53 & 33.8 & $26.8-41.5$ & 77 & 49.0 & $41.3-56.8$ & 16 & 10.2 & $6.4-15.9$ & 1 & 0.6 & $0.1-3.5$ \\
\hline $13-15$ & 175 & 3 & 1.7 & $0.6-4.9$ & 52 & 29.7 & 23.4-36.9 & 79 & 45.1 & $38.0-52.5$ & 36 & 20.6 & $15.3-27.2$ & 5 & 2.9 & $1.2-6.5$ \\
\hline $16-17$ & 111 & 1 & 0.9 & $0.2-4.9$ & 31 & 27.9 & $20.4-36.9$ & 57 & 51.4 & $42.2-60.5$ & 22 & 19.8 & $13.5-28.2$ & 0 & 0.0 & $0.0-3.4$ \\
\hline $6-17$ & 601 & 23 & 3.8 & $2.6-5.7$ & 198 & 33.0 & $29.3-36.8$ & 282 & 46.9 & $43.0-50.9$ & 92 & 15.3 & $12.7-18.4$ & 6 & 1.0 & $0.5-2.2$ \\
\hline
\end{tabular}




\section{Discussions}

The town of Miory is located in the northern part of Belarus, in the geochemical province of Poozerye, Minsk is located in the central part of Belarus. In the course of previous studies of the head size and shape of both the adult and child population of Belarus, it was found that the maximum values of the head length were observed in the Belarusians of the north region, especially in the north-west, and the minimum values - in the south of Belarus. The head breadth, on the contrary, is minimum in the north and south-east regions, and maximum in the west and in the center of the republic. Accordingly, the cephalic index is maximum in the southwest and west regions, and minimum - in the north-west and north-east (Salivon, 2011).

In our study, children of both sexes from Minsk throughout the whole period of the study had higher values of the head breadth (for boys 7-17 and girls 8-10 and 15 years old from $\mathrm{p}<0.05$ to $\mathrm{p}<0.001)$. Starting from the age of 13 in boys and 14 years in girls, the size of the head length of the Minsk dwellers is also greater (in boys - from $p<0.05$ to $p<0.001$ ). By the beginning of the definitive period (16-17 years), both young males and females of Minsk (the central region of Belarus) are distinguished by larger sizes of the head length and breadth, compared with their age mates from Miory (north-west). This may be due to different factors. Minsk is a megapolis, the center where people from all regions of Belarus come to. Due to such active population mixing, the results obtained can vary considerably. In Minsk economic prosperity is also much higher, living standards are higher, what could affect the magnitude of morphological parameters in Minsk children (their higher values).

By the size of the cephalic index from 7 to 15 years for boys (7-12 years old - from $p$ $<0.05$ to $\mathrm{p}<0.001$ ) and from 7 to 16 years for girls (at $8-11$ years old - from $p<0.05$ to $p<0.001$ ) children from Minsk are superior to their peers from Miory. By the beginning of the definitive period, somewhat high values of the cephalic index are observed in children of Miory, compared with their age mates from Minsk. The age variability of head sizes is due to the different growth rates of the head length and breadth and regional features of this process.

The leading morphotype for the two studied groups is brachycephalic. In Miory, the frequency of occurrence of the mesocephalic head shape is slightly higher, differences reach a high level $(\mathrm{p}<0.05)$ at $6-12$ years, as well as in the in the total sample. At the same time in Miory the frequency of the hyperbrachycephalic (in children 6-9 years old of both sexes and in girls in the total sample $-\mathrm{p}<0.05$ ) and ultrabrachycephalic shape (in boys in the total sample $-\mathrm{p}$ $<0.05$ ) is lower compared to Minsk. This corresponds to the tendency of a slightly more elongated head shape among the population in the north of the country, compared with the regions lying to the south, which was noted earlier by researchers (Salivon, 2011; Salivon, Polina and Marfina, 1989).

The head circumference and the skull capacity as early as at the age of 3-4 are very close to the "adult" values. It is known that the head length grows more intensively than its width. This results in elongation of the braincase shape, which does not occur immediately after birth, but, as a rule, somewhat later. After 12 months, in the opinion of the overwhelming majority of authors, there comes a period of very slow decrease in the index value, which lasts until maturity. The difference in the cephalic index between six months and 20 years rarely exceeds 1.5 units of the index (Khit, 1968; Miklashevskaya, Solovyova and Godina, 1988; Salivon, Polina and Marfina, 1989).

In our case, in Miory between 7 and 17 years of age, both in boys and the girls, the average values of the cephalic index increased by 1.6 units (groups of 6 year-old children are small in number), in Minsk - decreased by $04-0.8$. In general, there is a significant percentage of cases (slightly less than a quarter) when the head shape changes in the process of growth. It was determined that the growth process of the cranial part of the head mainly in vertical and transversal directions continues over the period of adolescence (Kuzmenko and Usovich, 2016). 
Obviously, most often this process is recorded in the case when the value of the cephalic index is close to the values delimiting adjacent morphotypes.

\section{Conclusions}

Thus, even within the limits of a fairly compact territory of one country, there are significant regional peculiarities in the variability of head shape indices (longitudinal and transverse diameter of the head, cephalic index). According to a longitudinal study, there was a decrease in the cephalic index between the ages of 7 to 17 in Minsk (by 0.4-0.8), and according to a transverse study, there was an increase in Miory (by 1.6).

The leading morphotype for the two studied groups is brachycephalic. In Miory, the frequency of occurrence of the mesocephalic head shape is slightly higher and the frequency of the hyperbrachycephalic and ultrabrachycephalic shape is lower compared to Minsk.

According to a longitudinal study, in $23 \%$ the head shape type between the ages of 6-7 differed from the shape between the ages of 16-17 years, usually $(19.2 \%)$ it was a transition from higher values to lower values (from brachymorphic to mesomorphic shape, etc.).

The results of the longitudinal study are more informative when analyzing the dynamics of a child's development, including basic head sizes. Changes in the head shape during the growth period should be taken into account when analyzing the variability of the cephalic index. The cephalometric studies in children and adults are important to clarify the epochal and regional variability of physical development, as well as necessary for practical medicine (injuries to the skull, oral and maxillofacial surgery, etc.).

\section{Acknowledgments}

The authors express their gratitude to Associate Professor, Cand. Sc. (History) V. Marfina, who also participated in the comprehensive study of the schoolchildren performed in the town of Miory, Vitebsk Region.

\section{Bibliography}

1. Akinbami, B.O., 2014. Measurement of Cephalic Indices in Older Children and Adolescents of a Nigerian Population. BioMed Research International, [e-journal] 8(2014), 5 pages, http://dx.doi.org/10.1155/2014/527473.

2. Alekseev, V.P., 1972. In search of ancestors. Moscow: Soviet Russia. [In Russian]

3. Bunak, V.V., 1941. Anthropometry. Moscow: Uchpedgiz. [In Russian]

4. Franco, F.C.M., Araujo, T.M., Vogel, C.J. and Quintão, C.C.A., 2013. Brachycephalic, dolichocephalic and mesocephalic: Is it appropriate to describe the face using skull patterns? Dental Press J Orthod, May-June; 18 (3), pp. 159-163.

5. Khit, G.L., 1968. Age variability of racial traits in the adult state. In: G.F. Debets and Y.Y. Roginsky (Ed.) Problems of the evolution of man and his races. Moscow: Science, pp. 124227. [In Russian]

6. Kouchi, M., 2000. Brachycephalization in Japan has ceased. Am J Phys Anthropol., 112 (3), pp. 339-347.

7. Kuzmenko, E.V. and Usovich, A.K., 2016. Kefalometric characteristics of men of military age living in the Republic of Belarus. Military medicine, 2, pp. 48-52. [In Russian]

8. Miklashevskaya, N.N., 1968. Sex differences in the growth of the head and face in children and adolescents. Questions of anthropology, 29. pp. 59-71. [In Russian] 
9. Miklashevskaya, N.N., Solovyova, V.S. and Godina, E.Z., 1988. Growth processes in children and adolescents. Moscow: Publishing House of Moscow State University. [In Russian]

10. Pavlica, T.M., Rakić, R.S., Božić-Krstić, V.S. and Srdić-Galić, B.Đ, 2018. Secular trend of head and face shape in adult population of Vojvodina (Serbia). Annals of Human Biology, 45(4), pp. 330-336.

11. Purunjan, A.L., Godina, E.Z., Khomyakova, I.A. and Zadorozhnaya, L.V., 2002. Features of epochal changes in the size of the body and head of children and adolescents of the Republic of Belarus and the Moscow region. Proceedings IV Int. congr. on integrative anthropology, pp. 299-301.

12. Rauten, A.-M., Maglaviceanu, C., Popescu, M.R., Martu, I., Popescu, D., Surlin, P., Suciu, M. and Bogdan M., 2014. Correlations Between Craniofacial Morphology and DentoMaxillary Anomalies in a Population of Children in The South West Region of Romania. Current Health Sciences Journal, 40(3), pp. 200-204.

13. Salivon, I.I., 2011. Changes in the physical type of the population of Belarus over the last millennium. Minsk: Belarusian Science. [In Russian]

14. Salivon, I.I., 2008. The process of formation of the proportions of the brain section of the skull of schoolchildren of Belarus in the early 1980s and 2000s. Actual issues of anthropology, 3, pp. 19-30. [In Russian]

15. Salivon, I.I., Polina, N.I. and Marfina, O.V., 1989. Children's organism and environment: Formation of a physical type in different geochemical regions of the BSSR. Minsk: Science and Technology. [In Russian]

16. Tineshev, S. and Dimov I., 2013. Cephalometric characteristics of children and adolescents from the eastern Rhodope region - Bulgaria. Glasnik Antropološkog društva Srbije, 48, pp. 43-47.

17. Vojdani, Z., Bahmanpour, S., Momeni, S., Vasaghi, A., Yazdizadeh, A., Karamifar, A.; Najafifar, A., Setoodehmaram, S. and Mokhtar, A., 2009. Cephalometry in 14-18 years old girls and boys of Shiraz-Iran high school. Int. J. Morphol., 27(1), pp. 101-104.

18. Williams, P., Dyson, M., Dussak, J.E., Bannister, L.H., Berry, M. M., Collins, P. and Ferguson, M.W.J., 1995. Gray's Anatomy. 38th Edition, London: ELBS with Churchill Livingston. 